\title{
Posibilidades de ahorro de energía en la industria del cemento
}

ANTONIO MARTIN MORALES

A P L E S A

\section{O. INTRODUCCION}

La fabricación de cemento es la industria que más fuel consume en España (2 MM t) después de las centrales térmicas; lo mismo ocurre en casi todos los países europeos. Por otra parte, la energía en todas sus formas es uno de los componentes principales del coste del cemento. Antes de la crisis energética se estimaba que esta partida suponía el $25 \%$ del precio del cemento: ahora supera el $35 \%$, de acuerdo con los siguientes consumos medios por $t$ de clínker.

\begin{tabular}{|c|c|c|c|c|c|c|}
\hline \multirow{5}{*}{$\begin{array}{l}\text { Fuel-oil } \\
\text { E. Eléctrica }\left({ }^{*}\right)\end{array}$} & \multicolumn{2}{|c|}{ Vía seca } & \multicolumn{2}{|c|}{ Vía semiseca } & \multicolumn{2}{|c|}{ Vía húmeda } \\
\hline & Consumo & Importe & Consumo & Importe & Consumo & Importe \\
\hline & $81 \mathrm{~kg}$ & 405 ptas. & $96 \mathrm{~kg}$ & 480 ptas. & $130 \mathrm{~kg}$ & 650 ptas. \\
\hline & $90 \mathrm{kWh}$ & 126 ptas. & $90 \mathrm{kWh}$ & 126 ptas. & $90 \mathrm{kWh}$ & 126 ptas. \\
\hline & & 531 ptas. & & 606 ptas. & & 776 ptas. \\
\hline $\begin{array}{l}\% \text { sobre precio ce- } \\
\text { mento }\left(*^{* *}\right)\end{array}$ & & 38 & & 43 & & 55 \\
\hline $\begin{array}{l}\% \text { sobre precio ce- } \\
\text { mento }(* * *)\end{array}$ & & 32 & & 37 & & 47 \\
\hline
\end{tabular}

(*) El consumo de energía eléctrica depende más de las circunstancias de cada instalación que del proceso. Se considera un consumb medio.

(**) Suponiendo que no se agregan aditivos.

(***) Suponiendo que el cemento lleva el $15 \%$ de aditivos.

Es evidente la gran importancia que los posibles ahorros de energía en la industria del cemento tienen tanto para la economía nacional como para la de los propios cementeros.

El cemento, como todos saben, se obtiene por calentamiento de una mezcla de arcilla y caliza a unos $1.450^{\circ} \mathrm{C}$. El conjunto de las reacciones que se producen hasta la obtención del clínker, de carácter fuertemente endotérmico, consume entre 380 y $440 \mathrm{kcal} / \mathrm{kg}$ de clínker, con un valor más frecuente de 420. 
La figura 1, tomada del libro "CEMENTO", de Fritz Keil, describe la serie de reacciones desarrolladas en la sinterización del clínker indicando las ecuaciones de reacción, numeradas de 1 a 9, expresadas esquemáticamente y la temperatura a la que se producen.

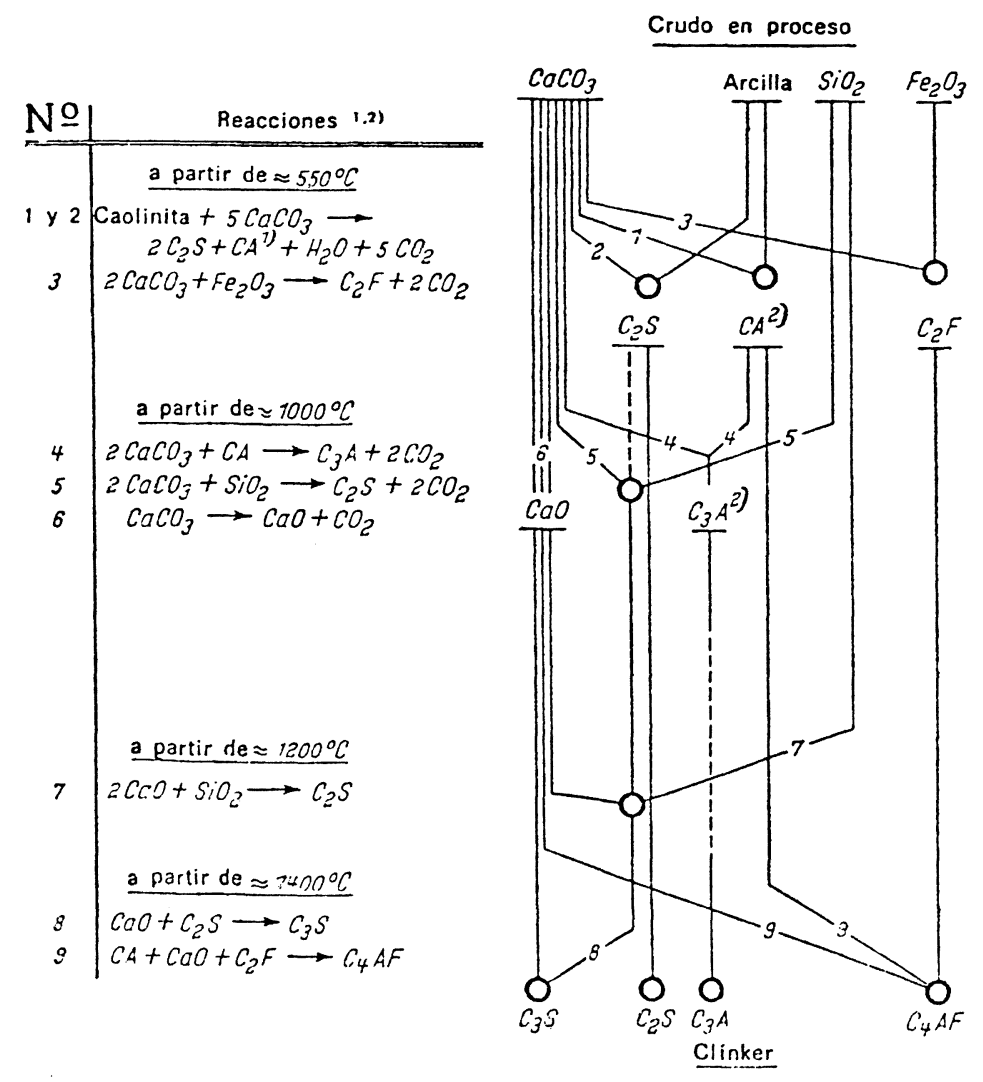

Fig. 1.- Serie de reacciones en la cocción del clínker, simplificadas esquemáticamente.

Tomados del mismo libro, seguidamente se exponen tres procedimientos, aplicados a un caso muy frecuente, para determinar el calor de clinkerización:

a) Cálculo a partir del análisis químico

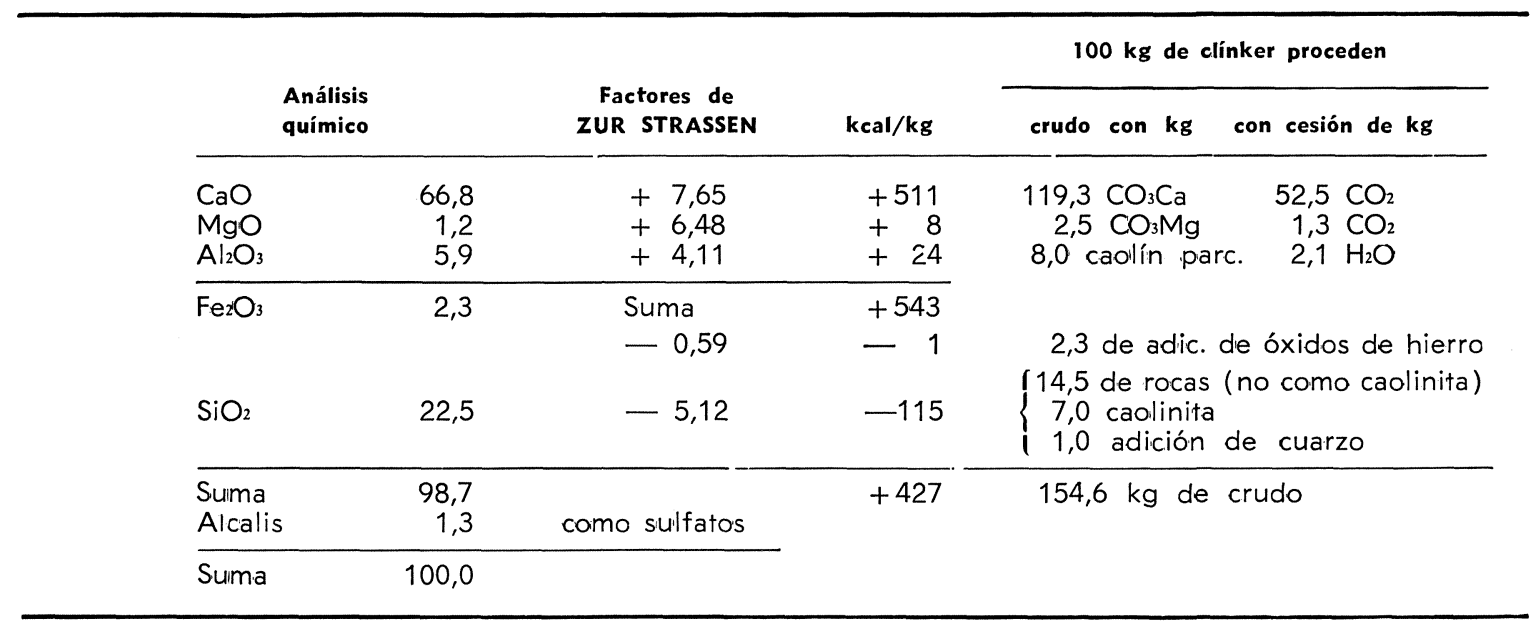


b) Cálculo a partir de las fases del clínker

\begin{tabular}{lrcr}
\hline \multicolumn{1}{c}{$\begin{array}{c}\text { Fases del clínker } \\
\text { según } \\
\text { BOGUE }\end{array}$} & $\begin{array}{c}\text { Entalpía de } \\
\text { reacciones reales }\end{array}$ & kcal/kg \\
\hline $\mathrm{SC}_{3}$ & 57,5 & $+4,37$ & +251 \\
$\mathrm{SC}_{2}$ & 21,2 & $+3,15$ & +67 \\
$\mathrm{AC}_{3}$ & 11,8 & $+6,03$ & +71 \\
$\mathrm{FAC}_{4}$ & 7,1 & $+4,05$ & +29 \\
$\mathrm{MgO}$ & 1,2 & $+6,54$ & +8 \\
& & & +426 \\
\hline
\end{tabular}

c) Cálculo a partir de los calores de reacción según la figura 1

\begin{tabular}{|c|c|c|c|c|}
\hline N.o & Reacciones & $\begin{array}{l}\text { Cantidad en } \\
\text { kg/clínker }\end{array}$ & $\begin{array}{ll}\text { Entalpías } \\
\text { de } \begin{array}{l}\text { reacciones } \\
\text { reales }\end{array}\end{array}$ & kcal/kg clínker \\
\hline 1 & Deshidratación de la caolinita & 0,150 & +109 & +16 \\
\hline \multirow[t]{2}{*}{$1-6$} & $\begin{array}{l}\text { Descarbonatación de: } \\
\text { hasta } \mathrm{CaO} \\
\text { (de } \mathrm{CO}_{3} \mathrm{Ca} \text { ) } \\
\text { hasta } \mathrm{MgO}\end{array}$ & $\begin{array}{c}0,668 \\
(1,193) \\
0,012\end{array}$ & $\begin{array}{l}+757 \\
(+424) \\
+654\end{array}$ & $\begin{array}{l}+506 \\
+\quad 8\end{array}$ \\
\hline & & & Neces. de calor & +530 \\
\hline \multirow[t]{3}{*}{8} & $\begin{aligned} \text { Formación de } & \mathrm{SC}_{3} \\
& \mathrm{SC}_{2} \\
& \mathrm{AC}_{3} \\
& \mathrm{FAC}_{4}\end{aligned}$ & $\begin{array}{l}0,575 \\
0,212 \\
0,118 \\
0,070\end{array}$ & $\begin{array}{r}-118 \\
-174 \\
-\quad 6 \\
-\quad 20\end{array}$ & $\begin{array}{r}-68 \\
-\quad 37 \\
-\quad 1 \\
-\quad 1\end{array}$ \\
\hline & & & Calor cedido & -107 \\
\hline & & & Diferencia & +423 \\
\hline
\end{tabular}

Para obtener el calor mínimo teórico total necesario para la producción de 1 kg de clínker, le debemos añadir la cantidad empleada en evaporar el agua contenida en las materias primas.

Este valor, en función de la humedad, es el siguiente:

\begin{tabular}{cc}
$\begin{array}{c}\text { Humedad crudo } \\
\% \text { b.h. }\end{array}$ & $\begin{array}{c}\text { Calor necesario } \\
\text { kcal/kg de clínker }\end{array}$ \\
\hline 1 & 10 \\
2 & 19 \\
3 & 29 \\
4 & 40 \\
5 & 50 \\
6 & 61 \\
7 & 71 \\
8 & 82
\end{tabular}

\begin{tabular}{cc}
$\begin{array}{c}\text { Humedad crudo } \\
\% \text { b.h. }\end{array}$ & $\begin{array}{c}\text { Calor necesario } \\
\text { kcal/kg de clínker }\end{array}$ \\
\hline 9 & 94 \\
10 & 105 \\
11 & 117 \\
12 & 129 \\
13 & 142 \\
14 & 154 \\
15 & 167
\end{tabular}

En la práctica la humedad suele oscilar entre el 8 y el $12 \%$. En la mayor parte de los casos, dadas las característicàs de las materias primas disponibles, el calor teórico mínimo para la obtención del clínker oscila entre 500 y $530 \mathrm{kcal} / \mathrm{kg}$ de clínker. A esta cifra le debemos añadir el calor que se pierde a través de la pared de los diversos elementos de la instalación, el calor perdido en las puestas en marcha y paradas, y el perdido por cau- 
sas diversas (refrigeración de elementos delicados, etc.). Resulta un consumo práctico en los procesos de vía seca pura con intercambiadores en suspensión de 720 a $750 \mathrm{kcal} / \mathrm{kg}$ de clínker. En los procesos por vía semiseca, como el proceso LEPOL, en el que se debe evaporar una cantidad adicional de agua, el agua de granulación, la cifra puede elevarse a $920 \mathrm{kcal} / \mathrm{kg}$. En los procesos semihúmedos, en los que la molienda se hizo por vía húmeda, pero se escurrió el crudo fuertemente por filtración, llegamos a las $970 \mathrm{kcal} / \mathrm{kg}$ como valor normal, y por último, en los procesos vía húmeda se llega a las $1.250 \mathrm{kcal}$.

La preocupación por el ahorro de energía en la industria del cemento no es una cosa nueva como consecuencia de la crisis energética que padecemos: desde hace muchos años se venía notando esa preocupación y prueba de ello es la evolución de los procesos y el ahorro logrado.

Hace 15 años había un claro predominio del proceso vía húmeda, pero actualmente todas las instalaciones que se montan son de proceso vía seca salvo imposibilidad debida a las características del crudo. La misma preocupación ha llevado a infinidad de estudios en todos los puntos del proceso, con logros valiosos, cuyo solo enunciado nos agotaría el escaso margen de tiempo disponible. Por ello voy a limitarme a comentar aquellos puntos que, a mi juicio personal, tienen mayor trascendencia con vistas al futuro.

\section{ADMISION DE ADITIVOS}

Ocupa el primer lugar una cuestión totalmente ajena a las técnicas de transferencia de calor, como es la regulación legal de los aditivos que pueden añadirse al clínker para obtener el cemento. Sobre este punto es interesante estudiar el ejemplo francés.

Hasta 1973 la relación clínker/cemento tenía en Francia un valor no inferior a 0,83. Las nuevas normas AFNOR, aparecidas en febrero de 1974, permiten disminuir el valor de esta relación. De esta forma el consumo de combustible necesario para la fabricación de una tonelada de cemento disminuye, ya que los aditivos no consumen energía exceptuada la de transporte y la necesaria para la molienda. En los seis primeros meses de 1974 la relación clínker/cemento bajó a 0,77: el consumo medio de energía por tonelada de cemento bajó en consecuencia en un $9 \%$. Para el año 1980 se espera que esta relación llegue en algunos cementos a 0,65. En 1973 los cementos que llevaban aditivos representaban el $62 \%$ de la producción; en 1974, el $75 \%$, y en 1980 se espera que una vez conocida mejor su utilización por los usuarios llegue a ser un $85 \%$.

Yo no soy especialista en cementos y desconozco las consecuencias técnicas que la variación de normas puede implicar; pero como especialista en consumo de energía veo que su trascendencia es enorme y que merece la pena estudiar la modificación de las normas vigentes.

\section{AUMENTO DE CAPACIDAD UNITARIA}

La segunda posibilidad que veo para reducir el consumo de energía es el aumento de capacidad unitaria de las instalaciones. Admitiendo procesos idénticos, las pérdidas "por radiación" se reducen cuando la capacidad de las instalaciones aumenta. Sin embargo, no es exactamente éste el camino que a mí me parece el más oportuno. 
El horno es un elemento caro, difícil de aislar, y con un flujo limitado de gases a su través; por ello creo que el horno se debe reservar para las reacciones que no pueden efectuarse en otro aparato. Si sacamos la descarbonatación fuera del horno, las necesidades caloríficas en el mismo disminuyen y disminuye también el flujo de gases de combustión por $\mathrm{t}$ de clínker. Como la velocidad de los gases en el horno es el condicionante que más limita la capacidad, es evidente que un horno dado aumentará su capacidad cuando su alimentación está muy descarbonatada. En este sentido es muy interesante el procedimiento japonés que sitúa quemadores en la base del sistema de intercambiadores en suspensión; pero este procedimiento no agota todas las posibilidades que se abren por este camino y el principio es aplicable a otros muchos procesos utilizando diversas técnicas.

\section{REDUCCION DE LAS PERDIDAS CON GASES FINALES}

Las pérdidas de calor con gases son proporcionales a su volumen y temperatura; por tanto para reducirlas conviene actuar sobre ambas variables.

\subsection{Reducción de aire falso}

\subsection{Calor perdido}

El calor perdido a causa del exceso de aire depende mucho del proceso. En dos casos extremos, proceso Lepol con salida de gases de la parrilla a $120^{\circ} \mathrm{C}$ y en un proceso Humboldt con salida de gases del intercambiador a $350^{\circ} \mathrm{C}$, suponiendo unos consumos normales de combustible, las pérdidas pueden evaluarse en:

\begin{tabular}{|c|c|c|c|c|}
\hline \multirow{2}{*}{$\begin{array}{c}\text { Exceso de aire } \\
\% \text { s/estequiométrico }\end{array}$} & \multicolumn{2}{|c|}{ Proceso Lepol } & \multicolumn{2}{|c|}{ Proceso Humboldt } \\
\hline & t de clínker & $\begin{array}{l}\text { kg fuel-oil } \\
t \text { de clínker }\end{array}$ & $\begin{array}{c}\text { kcal } \\
\text { t de clínker }\end{array}$ & $\begin{array}{l}\mathrm{kg} \text { fuel-oil } \\
t \text { de clínker }\end{array}$ \\
\hline $\begin{array}{l}10 \\
20 \\
30 \\
40 \\
50 \\
60\end{array}$ & $\begin{array}{r}3.700 \\
7.400 \\
11.100 \\
14.800 \\
18.500 \\
22.200\end{array}$ & $\begin{array}{l}0,48 \\
0,96 \\
1,45 \\
1,93 \\
2,41 \\
2,89\end{array}$ & $\begin{array}{r}9.490 \\
18.980 \\
28.470 \\
37.960 \\
47.449 \\
56.933\end{array}$ & $\begin{array}{l}1,24 \\
2,47 \\
3,71 \\
4,94 \\
6,18 \\
7,41\end{array}$ \\
\hline
\end{tabular}

En el proceso Humboldt se ha tomado la temperatura de salida de ciclones considerando que normalmente sólo los gases estequiométricos se emplean en el secado, y se pierde todo el calor arrastrado por el exceso de gases. 


\subsection{Eliminación del aire falso}

Vista la importancia que tiene la eliminación del aire falso, surge la pregunta de ¿cómo hacerlo?

Se puede optar por dos vías:

3.121. Cierre mecánico de todas las entradas

Esta solución debe aplicarse hasta donde sea posible económicamente. Sin embargo, no parece posible, en la práctica, la reducción hasta el $10 \%$ que sería deseable.

3.122. Instalación de quemadores auxiliares en la zona del precalentamiento del crudo

En estos quemadores puede reducirse el aire primario, y utilizaría como comburente el aire falso.

\subsection{Reducción de la temperatura de salida de los gases}

En el Proceso Lepol se alcanzan normalmente unas temperaturas óptimas.

En los Procesos vía seca la temperatura de salida oscila entre $330^{\circ}$ y $380^{\circ} \mathrm{C}$, lo que supone una pérdida notable de calor del orden de $190 \mathrm{kcal} / \mathrm{kg}$ de clínker. Este calor es utilizado parcialmente para el secado del crudo en la molienda. Dicho aprovechamiento resulta, sin embargo, limitado por dos razones:

- Con frecuencia, y muy especialmente en España, por su clima seco, las materias primas empleadas en hornos de intercambiador presentan un bajo contenido de humedad que hace inutilizables los excedentes caloríficos de los gases. Es de señalar, además, que los crudos con un contenido de agua hasta un $4 \%$ pueden secarse con las pérdidas caloríficas del enfriador.

- Aún con materias primas de humedad elevada, las limitaciones técnicas de los molinos en los que se efectúa el secado impiden el empleo total de los gases salida horno.

Puede decirse, pues, que, en numerosos casos se dan unas pérdidas de calor importantes.

La evolución actual y la predecible de los precios de los combustibles exige abordar el aprovechamiento integral del mismo en la fabricación de cemento. Sería por ello deseable reducir las salidas de calor sensible del horno a la cantidad estrictamente necesaria para el secado de materias primas, y ello teniendo en cuenta el aprovechamiento para el mismo fin de las pérdidas caloríficas del enfriador.

Una posible solución estaría en la ampliación a mayor número de etapas (cuatro en la actualidad) de los actuales intercambiadores de ciclones. La adición de más ciclones presenta, sin embargo, diversos inconvenientes:

- Aumento del tamaño y coste de la instalación, y también, en forma notable, de las pérdidas de carga del circuito, lo que obliga a un mayor consumo de energía eléctrica en el ventilador. 
- El intercambiador de ciclones es, por principio, discontinuo en su aprovechamiento energético. Cada nueva etapa introduce una variación discontinua en la temperatura de los gases de salida horno. Esto resta al sistema flexibilidad e impide ajustar la salida de calor a la cantidad necesaria para el secado, haciendo imposible el aprovechamiento integral de calor de que hablamos más arriba.

En relación con este asunto estamos estudiando una solución que puede encontrarse, bien en la sustitución de la etapa superior del intercambiador de ciclones, bien en la adición, al mismo, de cambiadores de calor del tipo que se esquematiza en la figura 2, en los que el crudo, mantenido en suspensión mediante una corriente recirculada, pasa por el interior de unos tubos en sentido ascendente, mientras que por otros, dispuestos en paralelo, circulan los gases calientes.

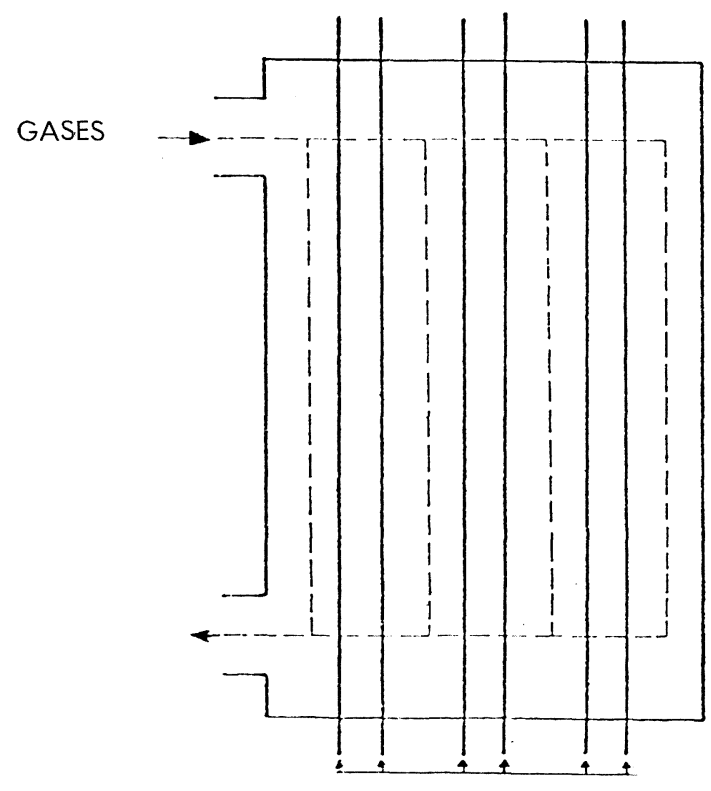

MATERIAL EN SUSPENSION

Fig. 2

En ensayos preliminares realizados en laboratorio se han encontrado coeficientes globales de transmisión de calor muy superiores a los normales en los cambiadores gas-gas. Esto permite predecir reducidas dimensiones del cambiador con disminución de la estructura y de la inversión necesarias para su montaje. De otra parte, dándole un mayor o menor dimensionamiento, se le podrá proyectar para conseguir a su salida cualquier temperatura que se desee, valor este que depende de las ulteriores necesidades del secado. Las variaciones en tales necesidades respecto a las previstas en el proyecto, por ejemplo: mayores humedades de las materias primas, podrían absorberse mediante la utilización de un by-pass, mucho más fácilmente acoplable aquí que a los intercambiadores de ciclones por cuanto éstos últimos pueden dejar de funcionar completamente, a efectos de intercambiadores térmicos, si el caudal de gases en los mismos no alcanza un determinado valor. Finalmente se espera alcanzar pérdidas de carga inferiores a las provocadas por los ciclones. 
La principal dificultad puede provenir de un fácil ensuciamiento del cambiador. El emplazamiento del mismo por encima de tres etapas de ciclones en zonas ya de temperaturas inferiores a los $550^{\circ} \mathrm{C}$ evitará la formación de pegaduras. Asimismo, y de acuerdo con los estudios preliminares, se prevén las siguientes posibilidades:

- Disposición constructiva, de forma que todos los tubos son accesibles para su limpieza mecánica interior.

- Adición de materias limpiadoras o inhibidoras de la formación de adherencias.

\section{MEJORA DEL RENDIMIENTO TERMICO EN LOS ENFRIADORES}

Más fácil es la recuperación del calor que actualmente se desperdicia en los enfriadores de parrilla tanto Recupol como Fuller. Actualmente en todas las etapas se inyecta aire frío, pero es posible establecer un flujo sólido/aire en contracorriente utilizando el aire a unos $250^{\circ}-300^{\circ} \mathrm{C}$ producido en la etapa más fría como aire de refrigeración para la etapa más caliente. Hasta hace poco se creía que esta técnica perjudicaba al clínker que necesitaba de un enfriamiento muy rápido para que no retrogradasen alguna de las reacciones más interesantes, pero ahora se ha comprobado que no es así, y que el clínker se puede enfriar gradualmente en un sistema en contracorriente. En las instalaciones intensivas con quemadores para producir la descarbonatación fuera del horno sobrará una cantidad importante de aire caliente si éste sólo se emplea en el mechero del horno; por ello en las instalaciones futuras convendrá situar el enfriador de tal forma que parte de este aire se pueda utilizar como aire de combustión en los quemadores secundarios.

Esta técnica implica la necesidad de ampliar los enfriadores, ya que a un gradiente de temperatura menor corresponde una menor transmisión de calor. Esto se puede hacer cómodamente en las nuevas instalaciones.

En las existentes cabe hacer un estudio cuidadoso de la variación del rendimiento en función de la velocidad de avance del clínker.

En los nuevos proyectos puede estudiarse el enfriador en tres etapas.

En las instalaciones LEPOL que utilizan el aire caliente de enfriadores para secado podrá tomarse una cantidad menor de aire a mayor temperatura, mejorando el rendimiento.

\section{CONTROL CONTINUO DEL CONSUMO ESPECIFICO DE COMBUSTIBLE}

Se puede obtener un ahorro de energía importante regulando perfectamente las instalaciones. Actualmente se emplean equipos muy completos para dosificar el crudo y ello está justificado. Sin embargo, el consumo de fuel únicamente se vigila con una instrumentación elemental. Para obtener una información exacta y continua, hemos desarrollado el procedimiento que les voy a exponer someramente. Se basa este procedimiento en que el análisis de gases en la chimenea es función de la composición del crudo y del combustible, del consumo específico del combustible, y del exceso de aire. La composición del combustible y del crudo se puede conocer perfectamente y, en consecuencia, una determinación de $\mathrm{CO}_{2}$ y $_{2}$ en los gases de chimenea permite determinar exactamen- 
te el consumo de combustible y el exceso de aire existente en aquel momento. Para un consumo conocido de combustible, la composición de los gases en los restantes puntos de la instalación será función del exceso de aire existente en aquel punto y del grado de descarbonatación del flujo sólido en el mismo. Un pequeño ordenador de procesos puede obtener al instante los valores que interesan y representarlos gráficamente si se dispone de plotter, o bien dar una tabla. Las operaciones son muy sencillas y se emplea una fracción muy pequeña de la capacidad del ordenador. El conocimiento instantáneo tanto del exceso de aire como del consumo de fuel permite vigilar mucho más de cerca la instalaciỏn, cerrar cualquier abertura por donde está entrando el aire falso o corregir cualquier otra causa del mayor gasto que se esté produciendo.

El único problema que presenta este procedimiento es la obtención de análisis fiables. En los gases finales no existe problema alguno, pues existen varios procedimientos capaces de determinar el $\mathrm{CO}_{2}$ y el $\mathrm{O}_{2}$ con un error muy pequeño y en este punto los gases están perfectamente homogeneizados. En otros puntos de la instalación la obtención de muestras representativas es más difícil debido a la diferencia de composición entre diversas venas gaseosas. Por ello antes de conectar unos analizadores continuos, en cuyas indicaciones nos apoyemos para regular el proceso, será preciso hacer un estudio estadístico de reparto de los análisis de las distintas tomas de gases y seleccionar un cierto número de tomas de muestras cuya composición sea representativa.

Este sistema de control puede ponerse en práctica preparando, para el crudo y fuel utilizados normalmente, un diagrama como el representado en la figura 3 ; sobre este diagrama se determina el consumo específico de fuel-oil.

Para cada consumo específico se puede preparar un diagrama análogo a la figura 4, sobre el que se llevan los análisis de gases en los distintos puntos para determinar en cada uno la descarbonatación del sólido y el exceso de aire.

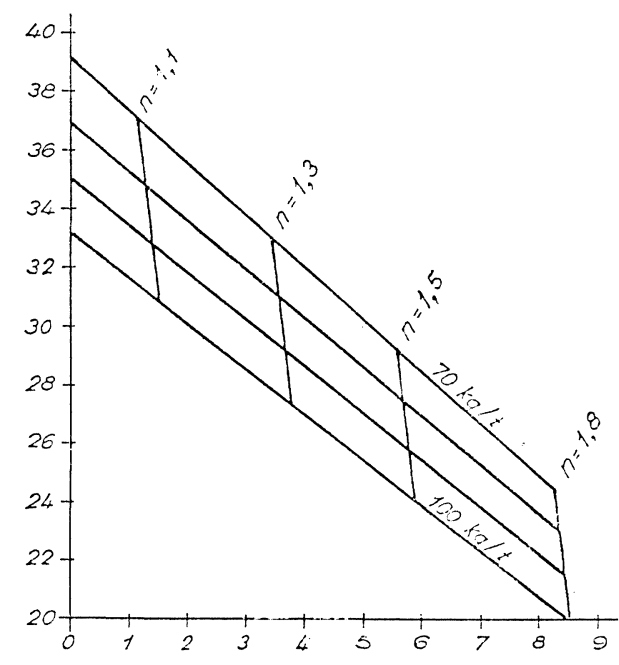

Fig. 3

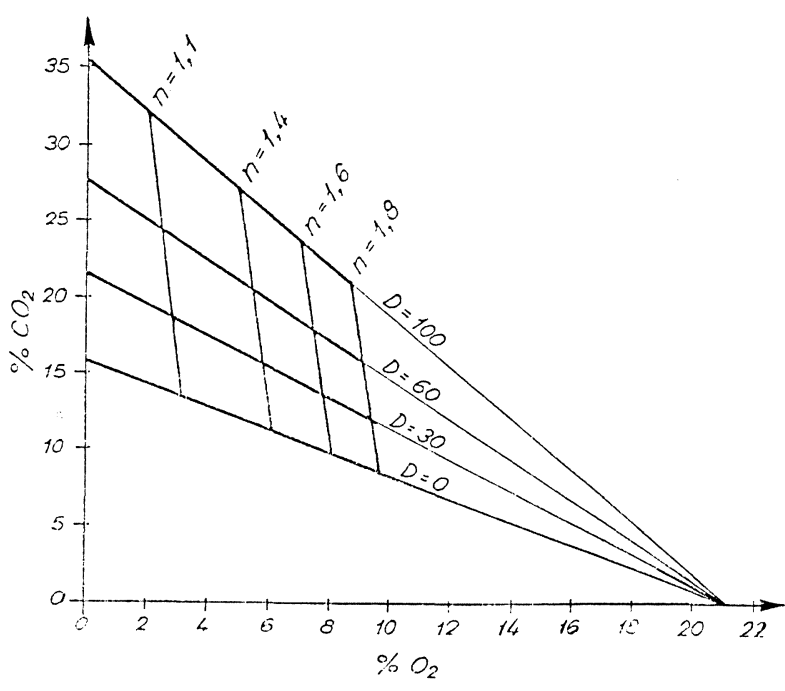

Fig. 4

El Listado 5 da los datos para preparar uno de estos diagramas.

El programa de ordenador que hemos preparado ofrece grandes ventajas sobre el cálculo gráfico, al tener en cuenta en cada instante todas las condiciones reales y, además, por la rapidez en la obtención de resultados. 
Este programa da directamente el consumo de fuel-oil y el exceso de aire (Listado 6).

Actualmente estamos trabajando para pasar de la fase "vigilancia" a la fase regulación, en un intento de que el ordenador produzca directamente las órdenes adecuadas para optimizar el consumo.

LIS TADO 5

Diagrama de combustión en el proceso de fabricación del cemento

\begin{tabular}{cc}
\hline DETERMINACION DE LAS LINEAS DE CONSUMO CONSTANTE $(\mathbf{N}=\mathbf{1})$ \\
\hline Consumo & T.P.C. de $\mathbf{C O}_{2}$ \\
\hline & \\
\hline 0.060 & 41.65 \\
0.065 & 40.24 \\
0.070 & 38.97 \\
0.075 & 37.83 \\
0.080 & 36.79 \\
0.085 & 35.85 \\
0.090 & 34.99 \\
0.095 & 34.20 \\
0.100 & 33.47 \\
0.105 & 32.79 \\
0.110 & 32.17 \\
\hline
\end{tabular}

DETERMINACION DE LAS LINEAS DE EXCESO DE AIRE

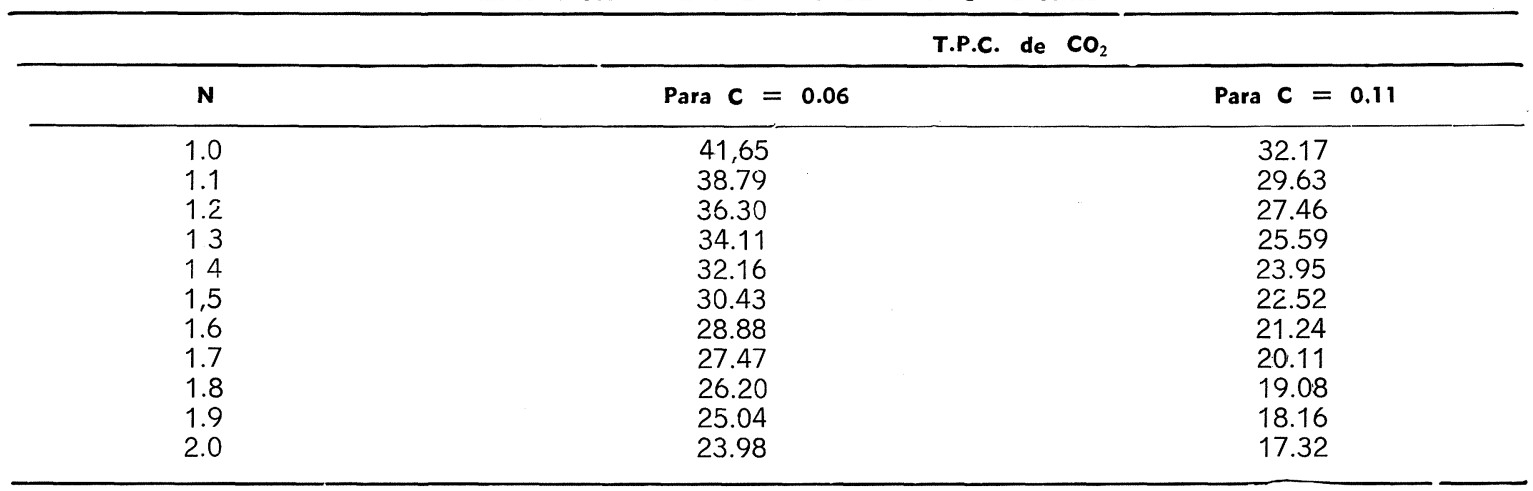

L I S T A D O 6

Control del consumo del combustible en la fabricación del cemento

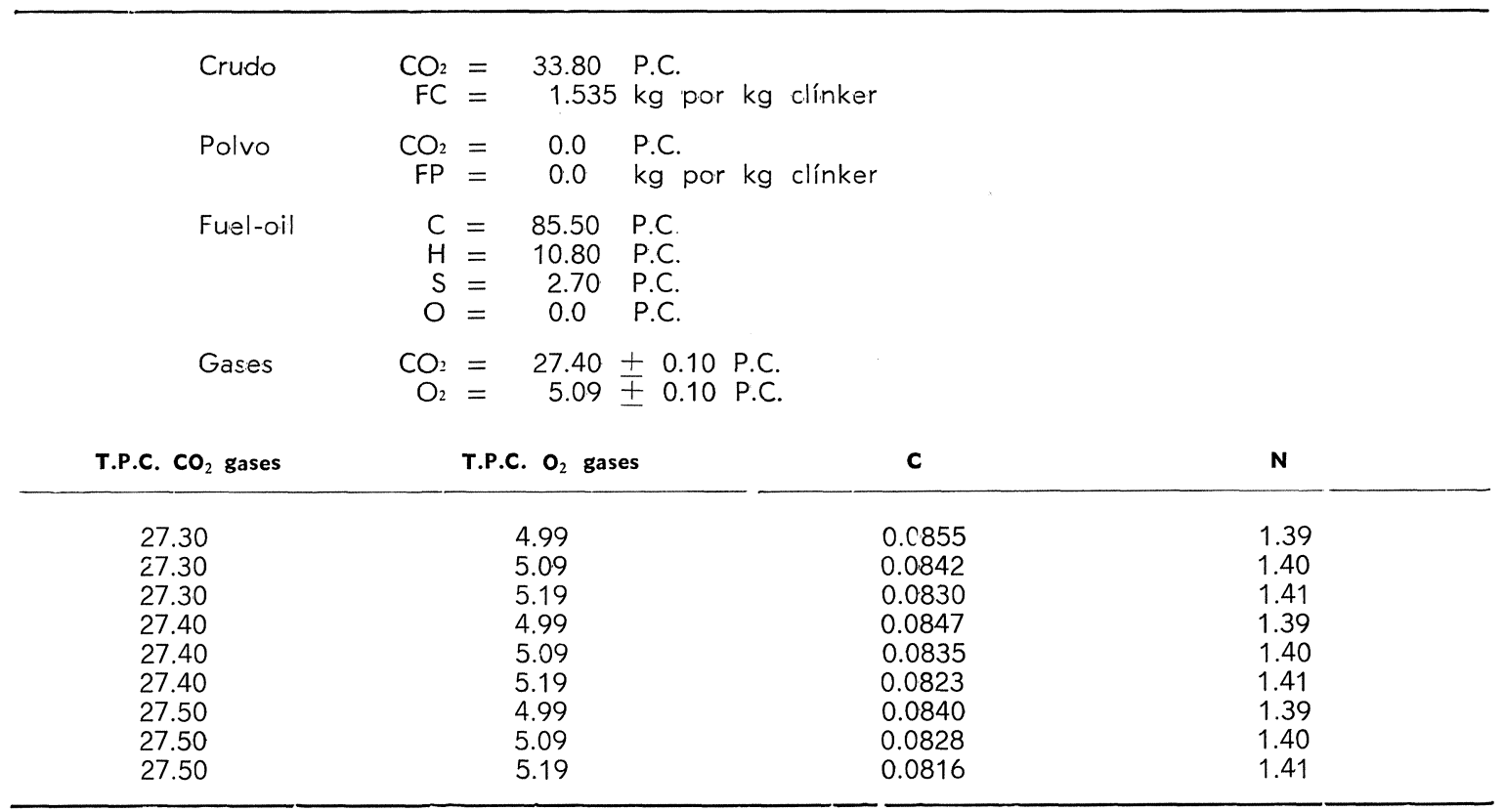




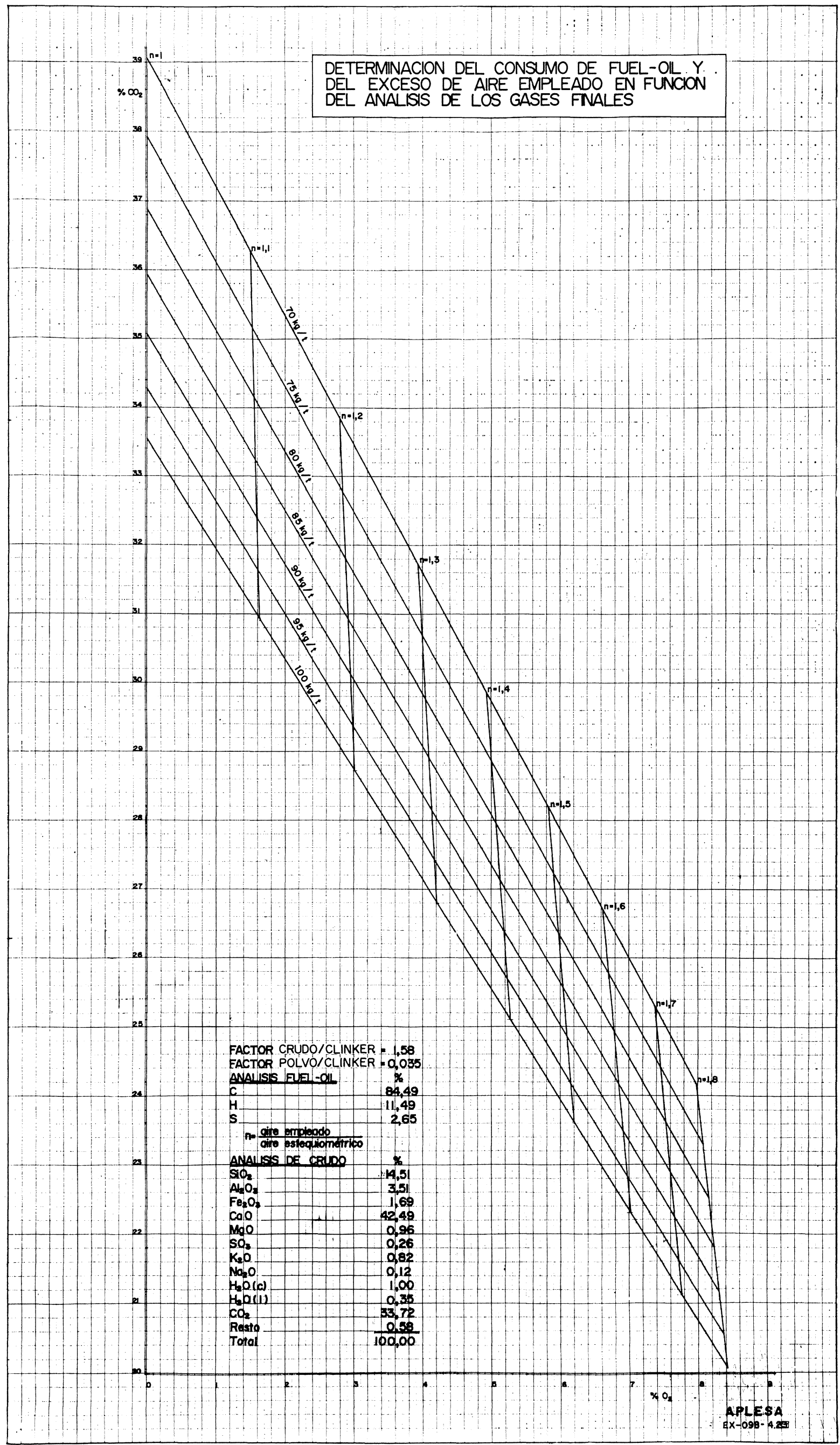




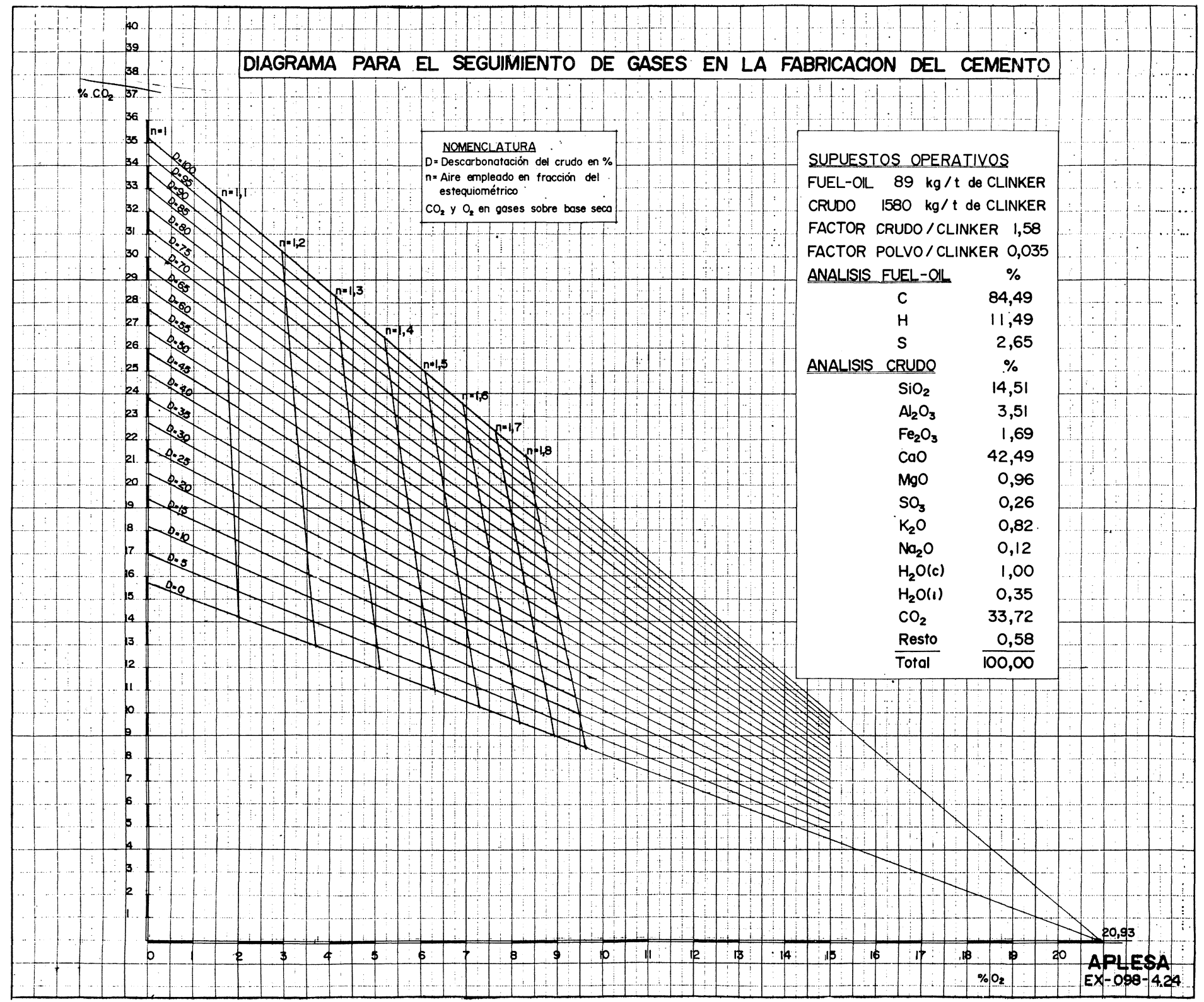




\section{OTRAS POSIBILIDADES}

No se pueden tratar, por falta de tiempo, otras muchas posibilidades de ahorro que enumero seguidamente a modo de índice:

6.1. Optimización del módulo de fundentes que permite cada crudo para bajar la temperatura de clinkerización.

6.2. En los procesos vía semiseca estudiar una molienda que no obligue al secado exhaustivo del crudo, ya que después se humedece en la nodulación. Sugiero la utilización de molinos pendulares que permitirían una humedad residual del $4 \%$ sin merma de la calidad de la molienda.

6.3. Optimización del grado de molienda del crudo: en muchas instalaciones la molienda se lleva más allá del límite necesario para la mezcla íntima de los componentes.

6.4. Presecado antes de la molienda de los crudos muy húmedos. Este presecado puede hacerse con gases más degradados.

6.5. Información a los consumidores de cemento sobre las calidades que necesitan para cada uso; yo creo que hoy día en gran parte de las obras se utilizan calidades de cemento más caras de lo que exige la naturaleza del trabajo. 


\section{COLOQUiO GENERAL SOBRE LA PRIMERA SESION DEL TEMA DEL AHORRO DE ENERGIA Y DE LOS COMBUSTIBLES}

Este Coloquio afectó en conjunto a las cuatro ponencias precedentes y fue presidido por el Sr. CALLEJA. Se desarrolló como sigue:

1. En relación con la primera ponencia, el Sr. VARGAS MUÑOZ corroboró lo expuesto por los autores de la misma, aportando datos de experiencia propia, según los cuales, la adición de yeso al crudo, cuando éste contiene muchos álcalis y se clinkeriza con gas natural pobre en azufre, permite fijar los álcalis y reducir las pegaduras en la cámara y a la entrada del horno, así como rebajar el consumo de combustible y aumentar la producción.

Lo atribuyó no sólo a la eliminación de pegaduras y al mayor paso de gases, sino también al efecto "mineralizador" del yeso, que aumenta la capacidad o aptitud del crudo para su cocción, reduciendo el contenido de cal libre del clínker. Resulta así —según señaló el opinante- que una adición de yeso del orden del $1 \%$ a crudos altos en álcalis fija éstos y disminuye las pegaduras en el sistema, y rebaja la cal libre del clínker y el consumo de combustible, al mismo tiempo que aumenta el rendimiento del horno.

2. El Sr. CALLEJA recapituló brevemente lo expuesto por el Sr. GIBERT acerca de la influencia del contenido, normal o añadido, de azufre en las materias primas y en el crudo -así como de $\mathrm{SO}_{2}$ y $\mathrm{SO}_{3}$ en el circuito del horno-, tanto en la fijación de álcalis como en la proporción de éstos que quedan libres para formar $\mathrm{KC}_{23} \mathrm{~S}_{12}$ y $\mathrm{NC}_{8} \mathrm{~A}_{3}$, fundamentalmente. Recordó el hecho puesto de manifiesto por el Sr. GIBERT de que un defecto de azufre en el crudo, o de $\mathrm{SO}_{3}$ en la atmósfera del horno, da lugar a clínkeres con más cal libre, más pobres en $\mathrm{C}_{3} \mathrm{~S}$, y a cementos de menor resistencia, sobre todo a largo plazo. Añadió que, sin embargo, echaba de menos algún comentario sobre el comportamiento de tales cementos en cuanto al fraguado, esto es, si era normal o anormal y, en este segundo caso, cómo se había intentado y conseguido corregir las anormalidades. Quiso saber también si se había encontrado una posible relación entre estos aspectos y la cantidad de yeso óptima que es preciso añadir al clínker para obtener, a igualdad de lo demás, incluida la finura, cementos de máxima resistencia y de mínima retracción.

Respondió el Sr. GIBERT diciendo que, en efecto, al principio, el cemento obtenido a partir del clínker cocido con gas natural y sin adición de yeso al crudo tenía un fraguado totalmente anormal, calentándose la pasta durante el amasado de la misma, como si se tratase de un falso fraguado. Péro que, una vez añadido yeso al crudo en la proporción señalada, el cemento resultante de moler el clínker con la proporción de yeso útil - ¿idónea, óptima? - tenía un fraguado normal, semejante al correspondiente a un cemento obtenido de un clínker comparable, cocido con fuel-oil.

\footnotetext{
* El contenido de este Coloquio, así como los de todos los sucesivos, están tomados al pie de la letra de la publicación de J. CALLEJA «Desarrollo de la actividad técnica de los Vlos Coloquios de Directores y Técnicos de Fábricas de Cemento" en la Revista CEMENTO-HORMICON, n.o 518 de marzo de 1977, y siguientes. Como allí se indica, responden íntegramente $y$ con todo detalle a lo tratado $y$ debatido en los mismos.
} 
3. El Sr. PAZ, de Colombia, dijo después que, dado el elevado costo del combustible en España, ¿cómo se lograba conseguir un cemento tan barato y de tan alta calidad? En relación con la mejora de ésta añadiendo yeso al crudo cuando se clinkeriza con gas natural, quiso saber en qué forma se efectuaba la adición y cuánto suponía ésta en costo por tonelada de clínker.

El Sr. GIBERT respondió que el precio del yeso venía a ser, en su caso, del orden de $170 / t$ y que se añadía en proporción aproximada de $1 \%$ en relación con el peso del crudo; y que la repercusión en el costo de la tonelada de cemento dependía en gran medida del costo de las restantes materias primas. En mi caso particular - dijo- en que una de las materias primas es bastante cara, la incidencia del yeso añadido al crudo en el costo del cemento es prácticamente insignificante.

4. A continuación el Sr. GARCIA CONDE habló de un problema planteado al Instituto del Carbón por las Centrales Termoeléctricas, en el sentido de aumentar el contenido de cenosferas de sus cenizas, aspecto al parecer importante - dijo- para la industria del cemento, pero sin que la industria termoeléctrica haya dado una explicación ni yo disponga de ella. Por ello - añadió- desearía que alguien, y no necesariamente ahora, se pusiera en contacto conmigo, para aclararme cuál es la ventaja de utilizar cenizas volantes en forma de cenosferas, en vez de cenizas normales de central termoeléctrica para la fabricación de cemento.

El Presidente, Sr. CALLEJA, dijo que la pregunta podría tener eco en varias personas informadas sobre el tema e interesadas en él, y que quedaba pendiente para posterior consideración y respuésta al Sr. GARCIA CONDE, en la que él mismo -el Sr. CALLEJA - tomaría parte.

5. El Sr. BALAGUER intervino después acerca de la calidad del carbón para hornos de cemento. Dijo que el más apropiado era el de 18 a $22 \%$ de volátiles; de 8 a $12 \%$ -ó 10 a $15 \%$ - de cenizas y con una humedad del orden del $2 \%$, una vez pulverizado. En cuanto a las cenizas - dijo-, si son calizas (como las de algunos lignitos) no descorrigen el crudo, y, si son arcillosas, la descorrección que producen en éste se compensa elevando su contenido de cal; pero si son altamente silícicas dan lugar a clínkeres que se autopulverizan, como personalmente había comprobado. Por otra parte, la retención de cenizas depende del tipo y del tamaño de los hornos (del orden del $56 \%$ en los de tiro libre de $54 \mathrm{~m} \times 3 \varnothing$, y del $82 \%$ en los LEPOL de la "época del carbón"); en los LEPOL, las cenizas pueden recubrir los gránulos y dar cementos rápidos y expansivos. Concluyó que si no se dispone de carbones que respondan a las características óptimas señaladas y con un poder calorífico de 6.800 a $7.200 \mathrm{kcal} / \mathrm{kg}$ se corre el riesgo de tener dificultades de fabricación y de producir cementos de comportamiento defectuoso en algún aspecto, hoy que tanto se le exige al hormigón y, por consiguiente, al cemento.

Respondió el Sr. GARCIA CONDE diciendo que conocía estos inconveniente en la utilización directa de los carbones, y que por ello su exposición la había orientado más bien hacia el empleo de derivados de la gasificación de los mismos o de residuos de la extracción de carbones por disolventes, procesos que pueden ser relativamente económicos y proporcionar combustibles homogéneos, prácticamente exentos de cenizas y con potencias caloríficas del orden de $9.000 \mathrm{kcal} / \mathrm{kg}$. Estos derivados — dijo-, no se parecen en nada al carbón original, pues carecen de sus cenizas y de su humedad, y contienen mucha mayor cantidad de volátiles que proporcionan una llama muy homogénea, aunque más larga. Por lo demás -añadió-, hoy se puede disponer de hullas de 18 a $22 \%$ de volátiles que se utilizan en la industria siderúrgica y que se lavan hasta rebajar las cenizas de sus finos y menudos a menos del $7 \%$, lo cual supone un avance frente a los carbones usados antaño en la industria del cemento, en cuanto a las dificultades que su utilización comportaba. Pero, en cualquier caso — concluyó- juzgo que más interesante 
que el empleo directo de los carbones puede ser la utilización de los productos de transformación de los mismos.

6. El Sr. AGUANELL formuló después las siguientes preguntas: ¿Cómo se transportarían y almacenarían esos carbones?; ¿qué mano de obra requeriría su manipulación?; ¿se podría seguir un proceso automatizado utilizándolos?

A ellas contestó el Sr. GARCIA CONDE diciendo que todo ello dependería del tipo de carbón que se utilizase, pero que insistía en que tal utilización sería siempre más difícil, y que por ello él prefería referirse a los transformados en vez de al carbón nativo. El transporte del carbón para producir gas "in situ" (en fábrica) - dijo-, sería el normal por tren o camión. En fábrica se clasificaría y gasificaría, almacenándose el gas en un gasómetro ordinario y procediendo como en el caso de utilización de gas natural. En cuanto a mano de obra, sería la precisa para una planta de gasificación altamente automatizada, incluido el transporte del gas al horno y, por lo tanto, muy pequeña.

Si se trata de hacer la extracción del carbón por disolventes y de utilizar el residuo de la extracción -añadió-, éste es un producto de análogas características que el carbón, si bien con mayor contenido de hidrógeno y mayor potencia ealorífica. Su transporte y almacenamiento (en parques, carboneras o silos) es, por lo tanto, igual al del carbón y, como éste, el residuo requiere una pulverización en molinos como los que todavía se utilizan, a los cuales se conduce por mecanismos automatizados, y de los cuales, por análogo sistema, va directamente a los quemadores mezclado con el aire primario, sin que todo ello suponga un aumento notable de mano de obra para las operaciones.

Todos estos procesos — dijo el Sr. GARCIA CONDE— están aún en vías de investigación y desarrollo, sin que todavía se haya procedido a la industrialización — suficientemente rentable--, ni de la gasificación del carbón, ni de su extracción por disolventes, aun cuando pueden ser soluciones de utilización futura. Siendo esto así -añadió-, de momento no cabe si no la utilización del carbón como tal, con sus problemas de transporte, almacenamiento, mano de obra y automatización, pues la posibilidad de transformar carbones en gas natural en España es remota y poco viable, ya que cada instalación necesaria -en desarrollo en los Estados Unidos- requiere 7 millones de toneladas de carbón homogéneo al año, lo cual es difícil de alcanzar, dadas nuestras actuales producciones y reservas. Por ello - dijo-, más que a la transformación del carbón en gas natural (metano), me inclino a su transformación en gas pobre (relativamente) y a su extracción por disolventes, como soluciones de aplicación práctica para pequeñas industrias.

El Sr. AGUANEL preguntó si en el caso de una fábrica de cemento ésta tendría que hacer la extracción de carbón, a lo que el Sr. GARCIA CONDE contestó que no, puesto que podría recibirlo ya extraído por instalaciones situadas en el punto de producción de los lignitos, en forma de granulado fino, pero no pulverizado, el cual habría que moler para darle la granulometría requerida por el carbón pulverizado para una buena combustión. A una nueva pregunta sobre la competitividad de estos procesos y combustibles con el fuel-oil contestó que, en la actualidad en los Estados Unidos se está desarrollando la gasificación para centrales térmicas, y que por los datos de que se dispone parece que son, no sólo competitivos, sino ventajosos y más económicos que la utilización directa de carbones con más del $30 \%$ de cenizas; lo cual hace pensar que en el caso de aplicación a la industria del cemento la competitividad con el fuel-oil puede ser aún mayor.

El Sr. AGUANEL recordó la transición del empleo del carbón al del fuel-oil, con las ventajas que ello supuso en cuanto a limpieza y facilidades de operación en las fábricas, y que volver de nuevo a la utilización del carbón supondría recaer en pasados inconvenientes. 
Respondió el Sr. GARCIA CONDE que, por otra parte, la industria del carbón también había avanzado y que, al poder ser éste gasificado, la situación en una fábrica de cemento sería similar a la de las industrias -incluida la cementera en algunos casos- que utilizan gas natural, sin excesivo detrimento de la limpieza y de la facilidad de operación.

7. El Sr. GRUA MESTRE, refiriéndose al ahorro de energía, invocó la conveniencia de rebajar la relación clínker/cemento para conseguirlo, a base de incorporar adiciones activas, lo cual no es problema en el caso de los cementos grises, pero sí en el caso de los cementos blancos en los que las adiciones no son activas, con lo que al no añadir ni éstas ni otras que lo sean, se muele clínker sólo, sin posibilidad de ahorrar energía en concepto de adiciones incorporadas.

El Sr. CALLEJA invitó a los presentes a opinar sobre el tema, antes de hacerlo personalmente.

El Sr. AGUANEL se manifestó en el sentido de negar la inactividad de la caliza.

Entonces el Sr. CALLEJA hizo alusión al nuevo Pliego español RC-75 de Recepción de Cementos, y dentro de él a los cementos blancos, indicando que la blancura es una de las cuatro propiedades adicionales que dicho Pliego atribuye en exclusiva a determinados cementos portland "puros" y a determinados cementos de tipo compuesto.

Añadió que, en efecto, según el Pliego RC-75 no cabe la posibilidad de incorporar al cemento portland blanco ninguna adición. Pero en cambio, a los cementos de tipo compuesto se les puede añadir hasta un $35 \%$ de materias "inertes", inøcuas, no nocivas, etc.; y que en el caso de tratarse de cementos compuestos blancos, estas materias deben ser tales que contribuyan a la blancura y no la perjudiquen. Ese es el caso del mármol - carbonato cálcico- blanco, cuya adición presenta otras ventajas. En efecto - dijo-, el clínker de cemento blanco, por razón de su naturaleza, está prácticamente exento de compuestos férricos, esto es, su alúmina forma casi exclusivamente aluminatos y, en particular, aluminato tricálcico. Por ello da lugar a cementos que, a igualdad o semejanza de lo demás, y sobre todo si se muelen a una finura mayor, tienen una capacidad de retracción mucho más elevada que los portland grises. Por otra parte - siguió diciendo-, los cementos blancos, salvo su empleo en hormigón estructural blanco o coloreado de cara vista, se utilizan para enlucidos, piedra artificial, baldosín hidráulico, terrazo, solados, etc., aplicaciones todas en las que el problema de la retracción es fundamental, y nefasto si no se tiene en cuenta y evita. De ahí que parezca evidente -prosiguió-, que para evitarla se añada a los clínkeres blancos una adición, incluso de las tenidas, en general, por inertes, del tipo del mármol blanco, tal que al diluir al cemento anula o atenúa la citada retracción y la fisuración consiguiente. Esta condición y este comportamiento los cumplen los cementos compuestos blancos, que pueden tener, como los grises, hasta un $35 \%$ de materia "inerte", y que son los cementos que hasta ahora se llamaban - y se seguirán llamando probablemente- "cementos blancos de albañilería y/o pavimentación".

Otra cosa es -concluyó el Sr. CALLEJA-, que el Sr. GRUA MESTRE eche de menos en el nuevo Pliego RC-75 un cemento portland PA blanco, o un cemento compuesto blanco con resistencias superiores a las del C-200-B. Lo que cabe decir al respecto es que tales posibilidades no se contemplan explícitamente en el Pliego, aunque la segunda queda implícita en el mismo.

8. A continuación el Sr. CORROCHANO dijo salir en defensa de los contadores de fueloil, por haberle parecido oir decir que el sistema actual de control del mismo es rudimentario y que resulta mejor el basado en el análisis de gases. Sin embargo -añadió-, el control del fuel-oil en fábrica es fiable y los contadores bastante precisos.

Contestó el Sr. MARTIN MORALES que los contadores de fuel unas veces miden bien y otras no tanto; pero que en todo caso miden un consumo que no es el específico, para el 
que se necesitarían los consumos instantáneos de fuel y de crudo, y que la medida exacta y simultánea de todos los datos necesarios es muy difícil. Por otra parte - prosiguió-, el procedimiento que he expuesto en mi ponencia no pretende desbancar a los demás, si no que es un complemento, que por dar una salida fácil para un ordenador permite transformar la señal correspondiente en una orden. Esto, unido a que lo que pretende y consigue el control por análisis de gases en una determinación continua del consumo específico, es decir, de la relación consumo de fuel a producción de clínker, constituye la principal ventaja del método.

El Sr. CORROCHANO puntualizó que todos los contadores de fuel que llevan transmisores eléctricos pueden dar indicaciones al ordenador, como sucede en general con cualquier instrumento actual de fábrica de cemento, el cual se monta con el ordenador y da una salida para éste. Insistió en la defensa de los contadores que funcionan bien y permiten un control cuantitativo de los materiales que entran en fábrica. En cuanto a los errores que puede haber en la determinación del consumo específico — dijo—, no se deben al sistema, sino a imprecisión de los instrumentos de medición de los caudales de materiales, aunque creo -añadió-, que los resultados de los analizadores de gases tienen imprecisiones como mínimo del mismo orden que de las básculas pesadoras.

Por su parte el Sr. MARTIN MORALES dijo que los analizadores de serie del mercado sí pueden tener tales imprecisiones, pero no los especiales, y que las desviaciones se producen mucho más como consecuencia de la toma de muestras que de los propios análisis; y que, en definitiva, el único sistema a su juicio bien resuelto para determinar el consumo específico del fuel, es el bașado en el análisis de los gases finales del proceso.

9. Acto seguido el Sr. LOPEZ SOLER, respecto del ahorro de energía por uno u otro procedimiento y concretamente en cuanto al aprovechamiento de los lignitos practicado hace mucho tiempo, preguntó que a dónde se había llegado con el mismo, que no fuera ya sabido. Respondió el Sr. GARCIA CONDE que, a su juicio, se estaba como hace diez años $\mathrm{o}$ aún peor, por el abandono total sufrido por el carbón en el mundo, frente a un petróleo abundante y muy barato. Pero que éste ya no es ni lo uno ni lo otro y que el problema futuro será más de escasez que de carestía, pues para el año 2.000 se prevé que las fuentes de energía primaria quedarán reducidas a la nuclear y al carbón. Y que como consecuencia - prosiguió-, el tema del aprovechamiento de los lignitos, como de los demás carbones, está empezando rápidamente a tomar interés en España, donde los lignitos uraníferos suponen quizás la mayor fuente de energía nativa que hay que explotar, para lo cual se han iniciado ya trabajos, aunque a nivel bajo y a ritmo muy lento, por las dificultades económicas.

A continuación el Sr. LOPEZ SOLER preguntó, sin ánimo de recibir respuesta, qué hacer frente a la Administración para fomentar la investigación y el estudio necesarios sobre el tema, como consecuencia de lo que se resuma y concluya de los presentes Coloquios.

El Sr. GARCIA CONDE consideró muy difícil contestar a la pregunta, pero opinó que lo que podía hacer la industria del cemento era expresar a los poderes públicos su preocupación por el futuro del combustible para ella, que - dijo-, indudablemente no será fuel-oil, ya que éste constituye una forma de infrautilizar el petróleo, el cual deberá destinarse forzosamente a fines más nobles.

Concluyó el Sr. LOPEZ SOLER - diciendo-, que el ritmo seguido para la sustitución del petróleo por otra energía o del fuel por otro combustible es tan sumamente lento que prácticamente no se avanza, y que sería preciso que de los Coloquios saliera algo positivo para una actuación inmediata al respecto.

10. Después intervino el Sr. HERRERA para manifestar su acuerdo con el Sr. CORROCHANO respecto de los contadores de fuel y de los medidores de crudo, y con el Sr. 
LOPEZ SOLER en cuanto a su postura relativa a la cuestión de la sustitución del fueloil. Se nos habla de ella - dijo-, pero no se llega a precisar su costo, y no se trata sólo de un problema de restricciones, sino también económico a toda escala. Preguntó luego en relación con el aprovechamiento de los gases de baja temperatura de los hornos y del aire de los enfriadores, ya que veía un contrasentido en dicho aprovechamiento, pues el de los primeros tiene lugar en la molienda de crudos, sobrando gases, con lo cual no se ve claro el eficaz aprovechamiento del segundo. Preguntó también acerca de las ventajas de los intercambiadores de calor sobre la marcha de los hornos y acerca de la combustión, es decir, sobre la forma en que se debe quemar el fuel-oil.

Le contestó el Sr. MARTIN MORALES, con respecto al aparente contrasentido que supone aprovechar gases de enfriador donde ya sobran gases, que ello depende del proceso, y que en el caso del LEPOL no hay gases de cola suficientemente calientes para el secado en la molienda del crudo, por lo cual, en dicho proceso está indicado para ello el aprovechamiento del aire del enfriador. En cambio - añadió-, en el proceso por intercambiadores en suspensión sí hay gases calientes de cola para el secado; y también hay exceso disponible de aire en los enfriadores de parrilla, mientras que no lo hay en los de tipo planetario. A mi juicio - continuó-, hay que tratar de aprovechar al máximo el calor de los gases de cola, calentando con ellos el crudo a través de unos primeros escalones de precalentamiento del mismo, y hay que utilizar el calor del aire de los enfriadores para el secado en molienda. Claro está que esto obliga a depurar mayor cantidad de gases en los electrofiltros. En resumen - dijo-, mi idea es la de tener gases de cola fríos habiendo aprovechado al máximo su calor para precalentar el crudo, y utilizar en el secado de éste el calor del aire de enfriador a una temperatura de 250 a $300^{\circ} \mathrm{C}$, o a $600^{\circ} \mathrm{C}$ aumentando las etapas de éste, con lo que se tiene un mayor rendimiento de secado en los molinos.

En cuanto al punto relativo a los intercambiadores el Sr. HERRERA -dijo-, que por éstos pasan los gases propios de la combustión y de la descarbonatación - sin contar el exceso de aire, muy controlado y limitado por varios conceptos-, los cuales al final del horno salen a una temperatura determinada, y cuyo calor hay que aprovechar; esto se hace en el propio intercambiador, pero a la salida del mismo hay aún un exceso de gases, todavía calientes, que sólo en parte se utilizan para el secado en la molienda del crudo. Ese resto de gases, que en la actualidad se enfrían - en general con agua - para hacerlos llegar a los filtros a temperatura conveniente, es el que se puede aprovechar recuperando su calor.

Se hizo la observación por parte del Sr. MARTIN MORALES de que esa solución deja sin empleo el exceso de aire de los enfriadores, a lo que el Sr. HERRERA - dijo-, que si se suma el calor que porta éste con el portado por los gases a la salida de los ciclones del recuperador se tiene una cantidad de calor sólo aprovechable para el secado en molienda, pero muy superior a la necesaria para ello.

El Sr. MARTIN MORALES aclaró que él había hablado de algo que está aún en vías de investigación preliminar, pendiente de la resolución de muchas dificultades y no de forma inmediata. Algo consistente en aprovechar aún más el calor de los gases de cola de los intercambiadores en suspensión para precalentar el crudo después de molido; y en utilizar para el secado previo de éste, durante la molienda, el calor de parte de los gases más calientes de los enfriadores, devolviéndose al horno el calor de la parte restante de dichos gases. Insistió en que una dificultad importante podría ser la exigencia de un nuevo diseño de electrofiltros de tamaño distinto, de acuerdo con el nuevo volumen de gases a tratar, en parte función de su temperatura más baja, y con el diferente contenido de humedad de los mismos.

En cuanto al cambiador de calor tubular, de corrientes contrarias y paralelas, en que una de ellas es la del polvo crudo, el Sr. HERRERA apuntó la posibilidad de formación 
de pegaduras, incrustaciones y películas aislantes en la pared transmisora, así como de obstrucciones en el conducto del crudo.

El Sr. MARTIN MORALES dijo no verlo así, dado que no se trata de un intercambiador clásico de tubos y carcasa, sino de una especie de bloque de tubos calentadores - con los gases-y de tubos calentados, - con la suspensión de crudo-, entre los que se establecen elevados coeficientes de transmisión. Las pegaduras no dependerían tanto de la presencia del polvo, como de las características granulométricas y electrostáticas del mismo, pudiéndose encontrar unas condiciones en las que el polvo actúe como un chorro de arena limpiador.

El Sr. HERRERA objetó que el polvo de crudo no es abrasivo como el del clínker, y que la distribución de velocidades entre el centro del tubo y las paredes hace que en éstas el régimen sea más laminar que turbulento, lo cual ayuda a crear las incrustaciones y capas aislantes.

Respondió el Sr. MARTIN MORALES que los resultados preliminares no señalan en gran medida tales dificultades, por otra parte previstas y que, de todas formas, los tubos deben ser fácilmente accesibles desde el exterior y en todo momento, para su limpieza.

Llegado el Coloquio a este punto, el Sr. CALLEJA consideró que el tema era muy sugestivo e interesante y que, ante la imposibilidad de matizar tanto detalle por el momento, sugería hacerlo en otra ocasión en privado -o en público si hubiera oportunidad-, y así se acordó.

A continuación el Sr. HERRERA, vista la conveniencia microeconómica de utilizar el fuel pesado, preguntó qué ahorro en pesetas supondría su empleo desde el punto de vista microeconómico del usuario.

El Sr. RUBIO dio su opinión personal, en el sentido de que la diferencia de precio entre el actual fuel-oil N. ${ }^{\circ} 2$ y el fuel pesado puede oscilar entre 4 y 10 dólares por tonelada. Citó de paso otro aspecto: el de la combustión. Los combustibles - salvo el queroseno que es gasificable - se queman sometiéndolos a una nebulización previa, dependiendo la combustión de factores como la pulverización del combustible, la turbulencia del aire comburente y la radiación en la cámara de combustión. Y en cuanto a la pulverización - dijo-, quemar fuel-oil pesado N.o 2 como si fuese fuel-oil pesado N. ${ }^{\circ} 1$ no tiene gran dificultad. En todo caso hay que llevar el nuevo combustible a una viscosidad igual a la del anterior, lo cual exige aumentar la temperatura de inyección en el sistema de preparación del combustible; de no poder hacerse esto, habría que aumentar la prèsión de inyección, lo cual no nos ofrece muchas posibilidades, puesto que la calidad de la gota -y la eficacia de la pulverización- es inversamente proporcional a la raíz cúbica de la presión de inyección. Otro recurso -añadió-, consiste en aumentar la turbulencia del aire primario de pulverización. En cuanto al factor económico —opinó-, quemar en condiciones una tonelada de fuel pesado $N . \circ 2$ puede exigir un consumo energético por valor de 15 a 20 pesetas/t, incluyendo la mayor potencia de bombeo, la mayor presión de inyección y el mayor calentamiento del combustible.

11. El Sr. MANNS, volviendo sobre el tema de la utilización de los lignitos, indicó que en otra sesión de los Coloquios se darían detalles acerca de la pregunta del Sr. LOPEZ SOLER sobre la posibilidad de utilizar carbones pobres en los hornos que se tienen, así como sobre la posibilidad de rebajar la temperatura de los gases de escape de los hornos.

12. El Sr. SITGES para quien como usuario del cemento - dijo-, éste es una materia prima del hormigón, sacó de nuevo el tema de las adiciones, a las que atribuyó ventajas al margen del ahorro de clínker y de energia. Al hormigón —continuó-, contractualmente se le exige siempre resistencia mecánica, pero pocas veces resistencia química; y al mismo tiempo su trabajabilidad es importante y depende en gran medida de las fraccio- 
nes finas de las arenas, que no siempre las poseen en la proporción adecuada. Mejorar la trabajabilidad del hormigón aumentando la dosis de cemento es antieconómico, pero puede lograrse con cementos con adiciones del orden del $30 \%$, por ejemplo. Añadirlas en obra tiene problemas de mezcla y homogeneidad, que quedan resueltos con su inclusión en fábrica, lo cual justifica los "cementos de adición", por los que abogó.

El nuevo Pliego RC-75 - prosiguió- recoge esta idea en los cementos siderúrgicos, puzolánicos y compuestos, los cuales permiten obtener hormigones de mayor trabajabilidad, compacidad, impermeabilidad y durabilidad, y de resistencia aceptable a 28 días. Pero, ¿qué pasará con ellos a los cuatro años, por ejemplo? - se preguntó-. Siendo partidario de las adiciones, creo - dijo- que éstas - y en particular las cenizas - deben estar sometidas a un control que garantice su calidad y la del cemento que las contiene, así como la constancia de dichas calidades.

Recogió el tema el Sr. CALLEJA, quien dijo que la respuesta a este planteamiento, unida a la de otro anterior hecho acerca de las cenizas volantes requeriría una ordenación de conceptos y un tiempo del que no se disponía, pero que sin embargo expondría brevemente algunas ideas. Las adiciones - prosiguió-, tanto si son activas como si no siéndolo, resultan inocuas, favorecen a los hormigones en aquellos casos en que el árido menos grueso - es decir, la arena- escasea en las fracciones más finas o carece de ellas. En tal caso, la presencia de tales adiciones molidas a la finura normal del cemento e íntima y homogéneamente mezcladas con él, mejora la trabajabilidad y contribuye a lograr unos hormigones más compactos y por lo tanto más durables químicamente hablando, porque el primer fallo del hormigón - sea cualquiera el cemento con el que esté hecho- frente a agresiones de tipo químico, es su falta de compacidad, su permeabilidad y penetrabilidad al agua o a los agentes agresivos de toda naturaleza.

En determinados países - continuó el Sr. CALLEJA- estos cementos no sólo están reconocidos en las normas, sino que su empleo está recomendado por las propias administraciones. Dentro de un conocimiento y de un control de los materiales -adicionesque se utilicen, y dentro de un comportamiento aceptable, perfectamente garantizado por la calidad de estos cementos - como preconiza el Sr. SITGES-, la solución aportada por ellos aun sin tener en cuenta el aspecto del ahorro energético, es buena. En tal sentido - dijo-, se incluye en el Pliego RC-75 los cementos portland con adiciones activas PA, en los que esta adición -escoria siderúrgica, puzolana natural o artificial, o ceniza volante- puede alcanzar la proporción del $20 \%$. Y en cuanto a resistencia mecánica, no se olvide el hecho importante de que, tan cemento de categoría 350 -por ejemplo- es un cemento portland con adiciones activas PA-350, como un cemento portland "puro" P-350, desde el punto de vista de la utilización. Y en cuanto al aspecto de la fabricación ello quiere decir que si el PA-350 está hecho con el mismo clínker que el P-350, el primero deberá ser más fino que el segundo; y si ambos están hechos con clínkeres distintos, y tienen la misma finura, el clínker del PA-350 deberá ser de categoría resistente superior a la del P-350. Y este razonamiento -añadió-, es perfectamente válido y trasladable a los cementos siderúrgicos y a los puzolánicos $\mathrm{y}$, en general, a todos aquéllos que contengan componentes secundarios o adicionales acompañando al clínker.

Sobre todos estos aspectos e ideas - concluyó-, se podría razonar y elucubrar mucho —no es este el momento-, pero ya se ha hecho bastante y poco a poco se irá haciendo más.

13. A continuación el Sr. HIDALGO DE CISNEROS formuló la siguiente pregunta que, a su juicio, había quedado flotando en el ambiente: ¿hacia dónde se va en cuanto al consumo de combustibles? Dijo por su cuenta que, a partir de la crisis del petróleo en noviembre de 1973 una firma - LOESCHE - recibió consultas en todo el mundo para transformar instalaciones de fuel-oil a carbón; consultas que, por lo que respecta a países industrializados, a tres años vista no han pasado de ahí, quedando archivadas; no se han 
hecho transformaciones fuel-oil a carbón, salvo en pocas instalaciones de Australia, Filipinas y Formosa. Lo único apreciado es que donde había instalaciones, mixtas o no, con antiguos molinos de carbón, éstos se han conservado, en lugar de ir a engrosar la chatarra. Por otra parte - prosiguió-, hoy ya no se habla del costo del fuel o del carbón, sino del costo de la caloría (la de cada combustible tiene un precio) con lo que en el futuro, y según mi opinión —dijo—, se evolucionará hacia la caloría de precio más bajo; y mientras la del fuel-oil siga siendo más barata que la del carbón se utilizará fuel, y se cambiará al carbón cuando ello deje de ser así.

A estas opiniones respondió el Sr. GARCIA CONDE, quien dijo que la avalancha de peticiones de información sobre transformación de hornos de fuel-oil a carbón, sin repercusiones posteriores, podía tener una explicación lógica. Efectivamente —dijo-, esa tendencia al cambio fue general en Europa ante el pánico energético, pero se tropezó con la grave dificultad, incluso en España, de que en los últimos años se habían cerrado prácticamente todas las minas de carbón existentes, por lo cual no fue posible - ni lo es en estos momentos en nuestro país - aumentar la producción de un día para otro y conseguir el suministro necesario. Eso -dijo-, puede explicar el que las transformaciones informadas no hayan progresado, lo que no quiere decir que no lo hagan dentro de unos años, cuando se pongan en explotación nuevas minas o se amplíe la producción de las existentes. A esto añadió el Sr. HIDALGO DE CISNEROS que la tendencia en el futuro puede ser hacia el carbón, pero que en estos momentos, por las dificultades de su explotación el problema es agudo, y que no hay forma de que la caloría del carbón salga más barata que la del fuel-oil, a pesar de las elevaciones del precio del petróleo.

Dijo después el Sr. GARCIA CONDE que, en el futuro, no tendrá tanta importancia el precio de la caloría del fuel o del carbón, como la disponibilidad de ellas, porque es muy probable, que, por unas razones u otras, en la mayor parte de los países escaseen tanto las caras como las baratas.

14. Intervino después el Sr. AGUANEL para decir que, como siempre, se había centrado la atención en la recuperación de todo el calor de los gases, pero que recientemente había recibido una oferta soviética para aprovechar, además, todo el calor de radiación del horno. El sistema - explicó-, parece consistir en una especie de camisa de agua alrededor del horno, y con él se consiguen, según la propaganda, ahorros hasta de $8.000 \mathrm{t}$ de carbón con potencia calorífica de unas $6.700 \mathrm{kcal} / \mathrm{kg}$, en una fábrica con una producción de 700.000 t/año.

15. El Sr. LOPEZ SOLER se refirió después a las exposiciones sobre el empleo de gas natural y fuel pesado, recordando que en ella se habían expuesto datos sobre los efectos del $\mathrm{SO}_{3}$, de los álcalis, de la cal libre, etc., y que en un trabajo presentado al $\mathrm{V}$ Congreso de Química del Cemento, de Tokyo, en 1968, había leído algo relativo a las acciones del potasio con el silicato tricálcico. Preguntó al Sr. GIBERT si había podido observar algo al respecto, y éste contestó que lo que había expuesto era el resultado de la interpretación de lo que ocurría en experiencias reales llevadas a cabo con el horno, en un intento de hallar una explicación teórica de los hechos, pero que no se había hecho ninguna observación en el sentido de la pregunta.

16. A continuación el Sr. CORROCHANO, con respecto a la última exposición sobre posibilidades de ahorro de energía, recordó al ponente, en relación con la recuperación de gases calientes de los enfriadores, que en la actualidad se suelen montar los de satélites, con los cuales lo expuesto acerca de la recuperación no es válido, y que en tal sentido convendría preguntar a los constructores de maquinaria presentes si se mantiene la tendencia hacia los enfriadores planetarios o de satélites, o si se dirige hacia los de parrilla.

En este punto el Sr. CALLEJA intervino para decir que tan interesante pregunta se había producido con anticipación, puesto que en otra sesión de los Coloquios se iba a 
tratar precisamente del estudio crítico y comparativo de los intercambiadores de calor convencionales, y que tal vez el Coloquio de dicha ponencia fuera el motivo y lugar para formular tal pregunta, cuando la respuesta no viniese dada implícitamente en el propio contenido de la ponencia.

1\%. El Sr. ESPI, refiriéndose a la intervención del Sr. SITGES relativa al interés de los cementos con adiciones activas, puzolánicos y ternarios para las empresas constructoras, preguntó que cómo siendo así que desde el 1 de junio está en vigor el nuevo Pliego de Recepción de Cemento RC-75, y que por lo tanto los mencionados cementos se podían fabricar ya legalmente, ahorrando además mucha energía, la Administración no fijaba los precios. Recabó una respuesta y una posible intervención por parte del Instituto Eduardo Torroja.

Se la dio a continuación el Sr. CALLEJA, contestando a las varias facetas que a su juicio implicaba la pregunta. En primer lugar —dijo-, en cuanto a las adiciones en general no olvidemos que hoy mismo tenemos una conferencia dedicada exclusivamente a ellas, a cargo del Sr. DUTRON, quien tratará del tema a la luz de las ideas europeas en general y belgas en particular. De acuerdo con su exposición y en el consiguiente Coloquio se podrá exprimir a fondo el tema.

Por otra parte - prosiguió-, el Instituto no ha intervenido ni interviene jamás en cuestiones de precios, por no ser de su incumbencia los aspectos económicos y sí sólo los científico-técnicos del cemento. En este sentido, en cuanto a la posibilidad de utilizar -incluso con ventaja - cementos que contengan adiciones, ese sí es un tema en el que el Instituto puede y debe intervenir, y de hecho virtualmente ya ha intervenido. Quiero decir -añadió-, que el Instituto tiene ya dispuesto para entregar a imprenta* un Código de Buena Práctica para el empleo de todos los cementos contemplados en el Pliego RC-75, en donde se señalan los empleos generales y específicos de cada tipo, clase y categoría de cemento, indicando para qué fines son aptos, señalando los casos y usos para los que están contraindicados, y llamando la atención sobre una serie de precauciones a observar en cada caso, cuando se emplean los cementos con una u otra finalidad y en unas u otras circunstancias. En este Código se da el tratamiento adecuado a todos los cementos que en una $\mathrm{u}$ otra forma y proporción contienen adiciones de todo tipo. Esto y algo semejante es cuanto se ha hecho y está haciendo en el aspecto técnico del empleo de los cementos.

En cuanto a problemas económicos y de mercado - continuó-, insisto en que no los toca el Instituto, puesto que para ello existe una Comisión de Precios, de la Administración. Se tratará el tema en estos Coloquios por parte de un miembro destacado de la misma, y ese será el momento de plantear el problema de los precios de los cementos y de urgir a la Administración para que dé al mismo soluciones eficaces y satisfactorias.

18. A continuación el Sr. DANEYKO volvió sobre el tema del aprovechamiento del calor de los gases, para decir que el de los calientes que están a temperaturas del orden de $600^{\circ} \mathrm{C}$ y superiores no ofrece problemas; pero que sí los ofrece el de los gases más fríos. Habló de una llamada "bomba de calor" suiza que, trabajando al parecer por un principio inverso al del frigorífico, permite recuperar el calor de baja temperatura de los gases fríos. Opinó que los gases fríos de la industria del cemento, después de haber sido aprovechados para secar o para precalentar, tienen pocas aplicaciones, y encontrar alguna satisfactoria supone un problema difícil pendiente de solución.

Respondió el Sr. MARTIN MORALES, diciendo, que, en efecto, el aprovechamiento total del calor de baja temperatura de los gases ya más fríos no está resuelto ni es totalmente soluble siempre, pero que en otras industrias se consigue más y mejor de lo

* En esta fecha ya está editado. 
que se hace en los hornos con intercambiadores en suspensión de la industria del cemento. La temperatura normal de los gases de escape en el caso de las calderas - dijo-, suele ser de 200 a $240^{\circ} \mathrm{C}$, con $100^{\circ} \mathrm{C}$ de diferencia con la de los gases de intercambiadores, lo cual invita a forzar más la recuperación, sobre todo ante el aumento de la carestía de combustible, siendo preciso tal vez para ello aumentar las inversiones con dicha finalidad.

El Sr. DANEYKO abundó en que en la mayoría de las fábricas de cemento el calor de los gases se aprovecha ya, desde un punto de vista térmico, casi lo más que se puede, dentro de lo que es fácil, y que tal vez un aprovechamiento más exhaustivo de éste requiriese pensar en transformarlo en otra forma de energía o en darle otras aplicaciones.

A esto respondió el Sr. MARTIN MORALES que tal transformación, concebible en teoría, es muy difícil en la práctica, y que pensar en otras aplicaciones exigiría la integración de la industria del cemento con otras industrias que pudieran aprovechar el calor de gases a baja temperatura, lo cual crea el problema de instalar al lado de las fábricas de cemento, industrias complementarias. Dio un ejemplo más sencillo, desde el punto de vista del mayor rendimiento energético, como es el del aprovechamiento del calor sensible del vapor de baja presión que sale de las turbinas de las centrales térmicas, en industrias químicas anejas a ellas. Esto - dijo-, se hace en algunos países del Este de Europa, donde las disposiciones se imponen por Decreto, pero que en España no se hace.

19. El Sr. HAAK dijo después que el aprovechamiento final de los gases residuales (a ciento y pico o a $380-400^{\circ} \mathrm{C}$ ) dependía de la humedad de las materias primas y del crudo.

El Sr. MARTIN MORALES dijo que sí, pero que de lo que se trataba no era del aprovechamiento de la fracción de gases que se utilizaban en el secado, sino del de la que se enfría para llevar a los electrofiltros - a temperatura mucho más baja-, y que no creía que se pudiera dar una solución general para el aprovechamiento en todos los casos, sino que el problema -y la solución-estaban en ahorrar el máximo de energía, dentro de unas inversiones razonables.

20. A continuación el Sr. SARABIA dijo haber entendido al Sr. MARTIN MORALES que se podía ahorrar energía en molienda haciendo que quedase en el crudo una humedad residual del $4 \%$, y que creía que esa humedad haría marchar mal el molino de bolas y, por supuesto, que creía que ocasionaría dificultades en los aerodeslizadores y demás sistemas de transporte y descarga.

Respondió el Sr. MARTIN MORALES diciendo que, en general, la humedad en determinadas cuantías perturba, y puso el ejemplo de los molinos de bolas que no pueden trabajar con humedades del material superiores al $1 \%$ y que, en su ponencia, ya había hecho alusión a molinos pendulares utilizados por otras industrias, con los que se muelen a finura equivalente a la de los crudos de cemento, materiales hasta con $4 \%$ de humedad residual. Añadió que, sin embargo no tenía referencias de su utilización en la industria cementera, donde serían muy útiles para evitar un secado excesivo de un material que después hay que humedecer, como sucede con el crudo para horno LEPOL, el cual después de secado y molido se ha de granular. En cuanto a cómo se comportaría a efectos de homogeneización y circulación en general -y con aerodeslizadores en particular- un crudo de cemento con un $4 \%$ de humedad residual, dijo que no lo sabía, pero que creía que mal. El Sr. BALAGUER añadió al respecto, corroborándolo, que un crudo con esa humedad tenía la máxima probabilidad de no salir de un silo, y que su experiencia personal era que la extracción sin problemas se podría realizar con humedades de hasta $1,5 \%$.

Y no habiendo más preguntas sobre el tema general del Ahorro de Energía, el Sr. CALLEJA levantó la sesión, agradeciendo a todos, expositores y participantes en el Coloquio, su presencia y actuación. 